\title{
SUPPLEMENT
}

\author{
Gozde Gultekin ${ }^{1}$ \\ Zeliha Kincir ${ }^{2}$ \\ Merve Kurt ${ }^{3}$ \\ Yasir Catal ${ }^{3}$ \\ Asli Acil $^{3}$ \\ Aybike Aydin ${ }^{3}$ \\ Mualla Ozcan ${ }^{3}$ \\ Busra N, Delikkaya ${ }^{3}$ \\ Selma Kacar ${ }^{4}$ \\ Murat Emuls
}

${ }^{1}$ Residency, MD, ${ }^{3}$ Medical Students, ${ }^{4}$ Nurse of Psychiatry, ${ }^{5} \mathrm{MD}$, Prof, Department of Psychiatry, Medical School of Cerrahpasa, İstanbul University, Istanbul, Turkey ${ }^{2} \mathrm{MD}$, Resident, Bakırkoy Mental Health and Neurology, Training and State Hospital, Istanbul, Turkey

\section{Facial emotion recognition ability: psychiatry nurses versus nurses from other departments}

\begin{abstract}
Purpose: Facial emotion recognition is a basic element in non-verbal communication. Although some researchers have shown that recognizing facial expressions may be important in the interaction between doctors and patients, there are no studies concerning facial emotion recognition in nurses. Here, we aimed to investigate facial emotion recognition ability in nurses and compare the abilities between nurses from psychiatry and other departments.
\end{abstract}

Methods: In this cross-sectional study, sixty seven nurses were divided into two groups according to their departments: psychiatry $(n=31)$; and, other departments $(n=36)$. A Facial Emotion Recognition Test, constructed from a set of photographs from Ekman and Friesen's book "Pictures of Facial Affect", was administered to all participants.

Results: In whole group, the highest mean accuracy rate of recognizing facial emotion was the happy (99.14\%) while the lowest accurately recognized facial expression was fear $(47.71 \%)$. There were no significant differences between two groups among mean accuracy rates in recognizing happy, sad, fear, angry, surprised facial emotion expressions (for all, $\mathrm{p}>0.05$ ). The ability of recognizing disgusted and neutral facial emotions tended to be better in other nurses than psychiatry nurses $(\mathrm{p}=0.052$ and $\mathrm{p}=0.053$, respectively)

Conclusion: This study was the first that revealed indifference in the ability of FER between psychiatry nurses and non-psychiatry nurses. In medical education curricula throughout the world, no specific training program is scheduled for recognizing emotional cues of patients. We considered that improving the ability of recognizing facial emotion expression in medical stuff might be beneficial in reducing inappropriate patient-medical stuff interaction.

\section{Correspondence to:}

Merve Kurt, Medical Student,

Medical School of Cerrahpasa,

İstanbul University, İstanbul, Turkey

E-mail:mervekurt@live.com 
Facial emotion recognition (FER) is one of the basic elements for proper socialization and personal interaction. Recognizing patients' emotional expressions seems important in patient-centered communication in medical settings [1]. Paul Ekman, the founder of FER research domain, has suggested that recognizing facial expressions may be important in interaction between doctors and patients [2]. The clinicians who are more accurate in recognizing the thoughts and emotions of their patients' are considered having more satisfied, adherent, engaged patients and more positive outcomes [3].

Appropriate nursing service is crucial for reducing patient's discomfort and pain [4]. Aggression and violence against health-care workers in clinical settings are well-known and are of increasing concern in recent years [5]. Although most human interactions and communications are non-verbal, there is no structured training in non-verbal communication in medical curricula alongside taking medical history, explaining medical intervention or giving bad news in health care education system [6].

In a meta-analysis study, important gaps have been reported in the existing evidence-based studies on FER [7]. In a recently published study [8], psychiatrist who identify themselves as psychotherapist were found to be better in recognizing sad facial expressions than psycho-pharmacologists. Moreover, some differences were reported among doctors from various departments according to the ability to recognize verbal emotional cues [9]. In addition, it has been suggested that empathy in medical students decreases throughout the course of their medical education [10]. There are no studies on FER ability in nurses, who are essential staff in all medical settings. We hypothesized that psychiatry nurses might have similar abilities to recognize facial emotions to nurses from other departments. We also hypothesized that there might be a positive correlation between duration of nursing and FER ability. We investigated FER ability in psychiatry nurses and nurses from other departments using a set of photographs from Ekman and Friesen's 1976 book "Pictures of Facial Affect".

\section{Methods}

\section{Participants}

The study was conducted with nurses from the various departments of Medical School of Cerrahpasa, and Bakirkoy Neurology and Mental Health, Research and Training Hospital in Istanbul between 1 November 2015 - 28 February 2016. Ninety six nurses were asked to participate to the study.
All participants were neurologically healthy, and none reported history of mental illnesses, organic brain injury or substance abuse. Upon giving oral informed consent anonymously, 67 nurses were included in the study while the rest of them declined to participate because of time constraints. The nurses were divided into two groups according to their departments: nurses from psychiatry $(n=31)$; and, nurses from other departments $(n=36)$. The study was approved by the local ethics committee.

\section{Procedure}

After filling out a socio-demographic questionnaire, all participants performed a facial emotion recognition test. The Facial Emotion Recognition Test was constructed using a set of photographs from Ekman and Friesen's book "Pictures of Facial Affect" [11]. The test included the photos of four male and four female models (a total of 56 photos) with happy, surprised, fearful, sad, angry, disgusted and neutral facial expressions. All photos were pressed on a white sheet $(210 \times$ $297 \mathrm{~mm}$ ) and patients were asked to recognize facial emotion expressions at a distance of $45-60 \mathrm{~cm}$. At first, we had a trial session, which was composed of the first seven photos and included each emotional facial expression (i.e., angry, sad, happy, neutral, fearful, disgusted and surprised) that was presented in the same order for each participant. A total of 49 photos were used for the data analyses in the study. In these photos, the relative numbers of the seven expressions were equal, ensuring that participants did not become overly familiarized with one specific emotional category. All participants were tested individually in a quiet room. No feedback was given regarding the appropriateness of their response.

\section{Statistical Analysis}

All statistical analyses were conducted with the Statistical Package for Social Sciences for Windows (SPSS) version 22.0. Demographic information was analyzed through descriptive statistics. Chi square test was used for categorical variables. Kolmogorov Smirnov test was used to test for normality. The mean accurate identifications of each facial emotion were compared with Student's T test or Mann Whitney U test. Correlation analysis was performed by Spearman correlation tests. A p value $<0.05$ was accepted as statistically significant. 


\section{Results}

All participants were female. There were no significant differences between psychiatry nurses $(\mathrm{n}=31)$ and other nurses $(\mathrm{n}=36)$ according to age $(36.77 \pm 10.44 v s .32 .72 \pm 8.41$ years $)$ and duration of working (12.61 $\pm 11.44 v s .10 .72 \pm 8.72$ years) $(p=0.083$ and $p=0.686$, respectively) $(p>0.05)$. Significantly, more nurses from other departments than psychiatry were smokers $\left(X^{2}=14.06\right.$ and $\left.\mathrm{p} \leq 0.001\right)$. Socio-demographical features of the participants were shown in Table 1.

In whole group, the highest mean accuracy rate of recognizing facial emotion was happy (99.14\%) while the lowest accurately recognized facial expression was fear (47.71\%). The accuracy rates of all nurses to each facial expression were shown in Table 2.

There were no significant differences between two groups among mean accuracy rates in recognizing happy $(\mathrm{p}=0.484)$, $\operatorname{sad}(\mathrm{p}=0.701)$, fear $(\mathrm{p}=0.277)$, angry $(\mathrm{p}=0.083)$ and surprised $(\mathrm{p}=0.358)$ facial emotion expressions. Although there were no statistical differences between groups according to mean accuracy rate of recognizing disgust and neutral facial emotion expression, the ability of recognizing disgusted and neutral facial emotions tended to be slightly better in other nurses than psychiatry nurses $(\mathrm{p}=0.052$ and $\mathrm{p}=0.053$, respectively). There was negative correlation between duration of working and recognizing fearful faces $(\mathrm{r}=-0.398$ and $\mathrm{p}=0.026)$ while positive correlation was detected between duration of working and recognizing disgusted faces $(\mathrm{r}=0.447$ and $\mathrm{p}=0.012)$ in psychiatric nurses. There was a positive correlation in non-psychiatry nurses between duration of working and recognizing angry faces $(r=0.333$ and $p=0.047)$.

TABLE 1. Socio-demographical features of the participants

\begin{tabular}{l|c|c|c}
\hline & $\begin{array}{c}\text { Psychiatry } \\
\text { nurses } \\
\mathbf{n}=31\end{array}$ & $\begin{array}{c}\text { Other nurses } \\
\mathbf{n}=36\end{array}$ & $\mathbf{p}$ \\
\hline${ }^{1}$ Age (years) & $36.77 \pm 10.44$ & $32.72 \pm 8.41$ & 0.083 \\
\hline $\begin{array}{l}\text { 2Duration of working } \\
\text { (years) }\end{array}$ & $12.61 \pm 11.44$ & $10.72 \pm 8.72$ & 0.686 \\
\hline $\begin{array}{l}\text { 3Marital status (married / } \\
\text { single) }\end{array}$ & $19 / 12$ & $19 / 16$ & $\begin{array}{c}\mathrm{X}^{2}=0.49 ; \\
\mathrm{p}=0.483\end{array}$ \\
\hline \begin{tabular}{l}
${ }^{3}$ Smoking (yes/no) \\
\hline${ }^{3}$ Alcohol use (yes / no))
\end{tabular} & $2 / 29$ & $0 / 36$ & $\begin{array}{c}\mathrm{X}^{2}=0.39 ; \\
\mathrm{p}=0.122\end{array}$ \\
\hline $\begin{array}{l}\text { 3Psychiatric drug use } \\
\text { (yes/no) }\end{array}$ & $2 / 29$ & $1 / 35$ & $\begin{array}{c}\mathrm{X}^{2}=0.49 ; \\
\mathrm{p}=0.483\end{array}$ \\
\hline
\end{tabular}

${ }^{1}$ With Student's T test, ${ }^{2}$ with Mann Whitney U test, ${ }^{3}$ with Chi square test, ${ }^{*}$ statistically significant
TABLE 2. Accuracy rate of all participants to each facial emotion expression

\begin{tabular}{l|c|c}
\hline \multirow{2}{*}{ Facial expressions } & \multicolumn{2}{|c}{ All nurses } \\
\cline { 2 - 3 } & mean \pm SD & $\%$ \\
\hline Happy & $6.94 \pm 0.30$ & 92.71 \\
\hline Sad & $5.24 \pm 1.52$ & 74.86 \\
\hline Fear & $3.33 \pm 1.80$ & 47.71 \\
\hline Angry & $6.04 \pm 1.04$ & 86.29 \\
\hline Surprised & $6.42 \pm 0.78$ & 91.71 \\
\hline Disgust & $5.36 \pm 2.25$ & 76.57 \\
\hline Neutral & $6.61 \pm 0.83$ & 94.43 \\
\hline
\end{tabular}

TABLE 3. Comparisons of mean accuracy rate according to nursing department

\begin{tabular}{|c|c|c|c|c|}
\hline Facial expressions & Groups & $\mathbf{n}$ & $\begin{array}{c}\text { Accuracy rate } \\
\text { mean } \pm S D\end{array}$ & $\mathrm{p}$ \\
\hline \multirow{2}{*}{${ }^{1}$ Happy } & Psychiatry nurses & 31 & $6.97 \pm 0.18$ & \multirow{2}{*}{0.485} \\
\hline & Other nurses & 36 & $6.92 \pm 0.37$ & \\
\hline \multirow{2}{*}{${ }^{1} \mathrm{Sad}$} & Psychiatry nurses & 31 & $5.16 \pm 1.83$ & \multirow{2}{*}{0.701} \\
\hline & Other nurses & 36 & $5.31 \pm 1.22$ & \\
\hline \multirow{2}{*}{${ }^{2}$ Fear } & Psychiatry nurses & 31 & $3.13 \pm 1.65$ & \multirow{2}{*}{0.277} \\
\hline & Other nurses & 36 & $3.50 \pm 1.94$ & \\
\hline \multirow{2}{*}{${ }^{1}$ Angry } & Psychiatry nurses & 31 & $6.00 \pm 1.16$ & \multirow{2}{*}{0.083} \\
\hline & Other nurses & 36 & $6.08 \pm 0.94$ & \\
\hline \multirow{2}{*}{${ }^{1}$ Surprised } & Psychiatry nurses & 31 & $6.32 \pm 0.79$ & \multirow{2}{*}{0.358} \\
\hline & Other nurses & 36 & $6.50 \pm 0.78$ & \\
\hline \multirow{2}{*}{${ }^{2}$ Disgust } & Psychiatry nurses & 31 & $4.48 \pm 2.90$ & \multirow{2}{*}{$0.052^{*}$} \\
\hline & Other nurses & 36 & $6.11 \pm 1.06$ & \\
\hline \multirow{2}{*}{${ }^{2}$ Neutral } & Psychiatry nurses & 31 & $6.42 \pm 1.06$ & \multirow{2}{*}{$0.053^{*}$} \\
\hline & Other nurses & 36 & $6.78 \pm 0.54$ & \\
\hline
\end{tabular}

' with Student's T test, ${ }^{2}$ with Mann Whitney U test, *trend of being significance 


\section{Discussion}

Recognizing emotional facial expressions play an important role in modulating interpersonal behavior. In this study, approximately nine of ten nurses were accurate in recognizing happy, surprised, neutral and angry faces. Happiness is accepted as a positive emotion and recognition of happy faces was preserved even in patients with schizophrenia [12] or euthymic bipolar disorder [13] and it was the most accurately recognized facial emotion in our nurses. Recognition of fear might somehow be more difficult [14] and has previously been reported to be frequently misinterpreted as surprise in healthy people [15]. Our findings of the lowest accuracy rate of recognizing facial emotions of fear support the general findings in healthy people. Aggressive people attribute fear faces when they are presented with ambiguous emotional faces [16]. In the current study, we have revealed that nurses have lower accuracy rate in recognizing fearful faces, which may be considered as they may interact with patients and/relatives of patients in somehow aggressive manner.

We did not find any differences in the ability to recognize facial emotions between psychiatry nurses and non-psychiatry nurses. Psychiatry nurses may be exposed more frequently to exaggerated facial emotions than non-psychiatry nurses in their clinical practice but nurses from other departments may also be exposed to exaggerated emotions as $74.4 \%$ of them have reported to have experienced some form of violence [5]. Furthermore, psychiatric disorders, including affective, somatic and anxiety disorders, are found at a rate between $42-66 \%$ in the general medical settings $[17,18]$.

For the first time, we have detected a trend of better recognizing of disgusted and neutral faces in non-psychiatry nurses than psychiatry nurses. We speculate that patients and/or relatives are frequently experiencing unfamiliar, awful odors and non-sterile medical waste in the general medical setting during hospitalization. Thus, non-psychiatry nurses may more frequently be faced with the disgusted faces of patients and/or their relatives than psychiatry nurses. Strikingly, there was a trend of being better recognizing neutral faces in non-psychiatry nurses than psychiatry nurses. Frequently, patients with psychiatric disorders have limited or blunted affect including schizophrenia or affective disorders $[19,20]$, or due to psychopharmacologic drug effect including antidepressants or antipsychotics [21,22] which may lead psychiatry nurses to be worse than non-psychiatry nurses in recognizing neutral facial expressions.

This study has several limitations. Small sample size was an important limitation of the study. Secondly, the cross-sectional design of this study did not allow us to understand possible alterations in FER ability as a function of working years. Thirdly, although all nurses were uneventful in their working environment, other possible factors including burnout, depression and anxiety should be kept in mind.

In conclusion, this study was the first that revealed absence of differences in FER abilities between psychiatry nurses and non-psychiatry nurses. In medical education curricula throughout the world, there is no specific training in recognizing emotional cues of patients [7]. Studies on improvements in the ability to recognize facial emotion expressions after training are growing in the literature. Thus, improving the ability to recognize facial emotion expression in medical staff might be beneficial in reducing inappropriate patient-medical staff interaction.

\section{References}

1. Blanch-Hartigan D. Medical Education. An effective training to increase accurate recognition of patient emotion cues. Patient Educ and Couns. 2012;89:274-280

2. Ekman P, Yamey G. Emotions revealed: recognizing facial expression. Careerfocus 2004:75-76

3. Blanch-Hartigan D, Ruben MA. Training clinicians to accurately perceive their patients: current state and future directions. Patient Educ Couns. 2013;92:328-36.

4. Azma K, Goodarzi N, Tavakolian E, Yadegarian F. The Difference between Mu Suppression and Nurses' Empathy with the Difference of Three Years of Work Experience. Mater Sociomed. 2015;27:417-20.

5. Kaya S, Bilgin Demir İ, Karsavuran S, Ürek D, İlgün G. Violence Against Doctors and Nurses in Hospitals in Turkey. J Forensic Nurs. 2016;12:26-34.

6. Riess H, Kraft-Todd G. E.M.P.A.T.H.Y.: A Tool to Enhance Nonverbal Communication Between Clinicians and Their Patients. Acad Med. 2014;89:1108-1112.

7. Hartigan DB, Ruben MA. Training clinicians to accurately perceive their patients: Current state and future directions. Patient Educ Couns. 2013;92:328-336.

8. Varkal MD, Gultekin G, Yuksek E, Varsak N, Gul H, Kıncır Z, Tasdemir A, Emul M. Facial Emotion Recognition in Psychiatrists and Influences of Their Therapeutic Identification on that Ability. Comp Psyc, 2016; 69: 30-5

9. Endres J, Laidlaw A. Micro-expression recognition training in medical students: a pilot study. BMC Med Educ. 2009;9:47.

10. Hojat M, Vergare MJ, Maxwell K, Brainard G, Herrine SK, Isenberg GA, Veloski J, Gonnella JS. The devil is in the third year: a longitudinal study of erosion of empathy in medical school. Acad Med. 2009;84:1182-1191.

11. Ekman P, Friesen W (1976) "Pictures of Facial Affect". Palo Alto, Consulting Psychologists. 
12. Demirbuga S, Sahin E, Ozver I, Aliustaoglu S, Kandemir E, Varkal MD, Emul M, Ince H. Facial emotion recognition in patients with violent schizophrenia. Schizophr Res. 2013;144:142-145.

13. Demirel H, Yesilbas D, Ozver I, Yuksek E, Sahin F, Aliustaoglu S, Emul M. Psychopathy and facial emotion recognition ability in patients with bipolar affective disorder with or without delinquent behaviors. Compr Psychiatry. 2014;55:542-546.

14. Tse WS, Yan L, Bond AJ, Chan RC, Tam DW. Facial emotion linked cooperation in patients with paranoid schizophrenia: a test on the Interpersonal Communication Model. Int J Soc Psychiatry. 2011;57:509-517.

15. P. Ekman Facial Expressions T. Dalgelish, M. Power (Eds.), Handbook of Cognition and Emotion, Wiley \& Son, New York (1999).

16. Weiss EM, Kohler CG, Nolan KA, Czobor P, Volavka J, Platt $\mathrm{MM}$. The relationship between history of violent and criminal behavior and recognition of facial expression of emotions in men with schizophrenia and schizoaffective disorder. Aggress Behav. 2006;32:187-194.
17. Alkhadhari S, Alsabbrri AO, Mohammad IH, Atwan AA, Alqudaihi F, Zahid MA. Prevalence of psychiatric morbidity in the primary health clinic attendees in Kuwait. J Affect Disord. 2016;195:15-20.

18. Fullerton C, Florenzano R, Acuña J. Comorbidity of chronic diseases and psychiatric disorders among patients attending public primary care. Rev Med Chil. 2000;128:729-734.

19. Kilian S, Asmal L, Goosen A, Chiliza B, Phahladira L, Emsley R. Instruments measuring blunted affect in schizophrenia: a systematic review. PLoS One. 2015;10(6):e0127740.

20. Caouette JD, Guyer AE. Cognitive distortions mediate depression and affective response to social acceptance and rejection. J Affect Disord. 2016;190:792-799.

21. Kirkpatrick B. Developing concepts in negative symptoms: primary vs secondary and apathy vs expression. J ClinPsychiatry. 2014;75:3-7.

22. Kirkpatrick B. Progress in the study of negative symptoms. Schizophr Bull. 2014;40:S101-106. 